\title{
Vademecum für den An- und Verkauf von Apotheken
}

nebst Anhang

Anleitung für die Buchführung in einer Apotheke mit Rücksicht auf die Steuerdeklaration

\section{Von \\ G. Unruh}

Apothekenbesitzer, Bad Kösen

Beeidigter Taxator für Apothekenwerte

Zweite, verbesserte Auflage

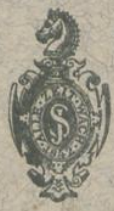

Berlin

Verlag von Julius Springer 1920 
Verlag von Julius Springer in Berlin.W.9

Hager's Handbuch der Pharmazeutischen

Praxis für Apotheker, Arzte, Drogisten u. Medizinalbeamte.

Hauptwerk: Unter Mitwirkung von Max Arnold-Chemnitz, G. Christ-Berlin, K. Dieteridh-Helfenberg, Ed. Gifdemeister-Leipzig, P. Janzen-Perleberg, G. Scriba-Darmstadt, vollständig neu bearbeitet und herausgegeben von B. Fischer-Breslau und C. Hartwich-Zürich. Mit zahlreichen in den Text gedruckten Holzschnitten. Zwei Bände. Neunter, unveränderter Abdruck. Unter der Presse

Ergänzungsband: Unter Mitwirkung von Ernst DuntzeBerlin, M. Piork owski-Berlin, A. Schmidt-Geyer, Georg Weigel-Hamburg, Otto Wiegand-Leipzig, Ca rl WulffBuch, Franz Zernik-Steglitz, bearbeitet und herausgegeben von W. Lenz-Berlin und G. Arends-Chemnitz. Mit zahlreichen in den Text gedruckten Abbildungen. Vierte r, unveränderter Abdruck Unter der Presse

Kommentar zum Deutschen Arzneibuch 5. Ausgabe 1910. Auf Grundlage der Hager-Fischer-Hartwichschen Kommentare der früheren Arzneibücher unter Mitwirkung von Prof. Dr. J. B iberfeld-Breslau, Dr. P. W. Danckwortt-Breslau, Dr. G. Fromme-Halle a. S., F. M. Haupt-Greifswald, Dr. M. Pleißner-Dresden, Prof. Dr. H. S chulze-Halle a. S., Dr. W. Stüwe-Tena, Dr. O. WiegandLeipzig, herausgegeben von Dr. O. Anselmino, Privatdozent an der Universität Greifswald, und Dr. Ernst Gilg, a. o. Prof. der Botanik und Pharmakognosie an der Universität, Kustos am Botanischen Museum in Berlin. Zwei Bände mit zahlreich. Textabbildungen. Preis je M. 15.-, geb. M. 17.50

Handbuch der Drogisten-Praxis. Ein Lehr- und Nachschlagebuch für Drogisten, Farbwarenhändler usw. Im Entwurf vom Drogisten-Verband preisgekrönte Arbeit. Von G. A. Buchheister. Dreizehnte, neubearbeitete und vermehrte Auflage von Georg Ottersbach in Hamburg. Erster Teil. Mit 585 Abbildungen. Preis gebunden M. 26.-

Vorschriftenbuch für Drogisten. Die Herstellung der gebräuchlichsten Verkaufsartikel. Von G. A. Buchheister. Achte, neubearbeitete Auflage von Georg Ottersbach in Hamburg. Preis gebunden M. 28.-

Hierzu Teuerungszuschläge.

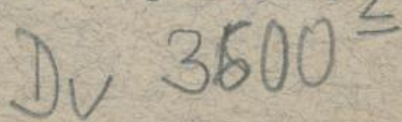




\title{
Vademecum für den An- und Verkauf von Apotheken
}

\author{
nebst Anhang
}

Anleitung für die Buchführung in einer Apotheke mit Rücksicht auf die Steuerdeklaration

\section{Von \\ G. Unruh}

Apothekenbesitzer, Bad Kösen

Beeidigter Taxator für Apothekenwerte

Zweite, verbesserte Auflage
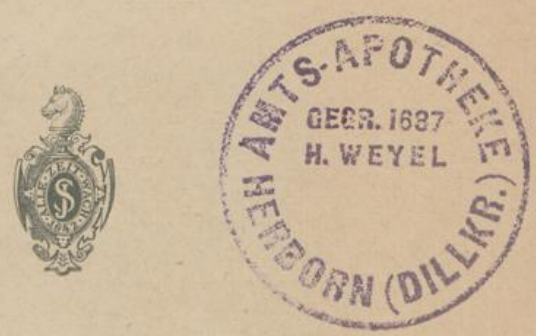

Berlin

Verlag von Julius Springer

1920 


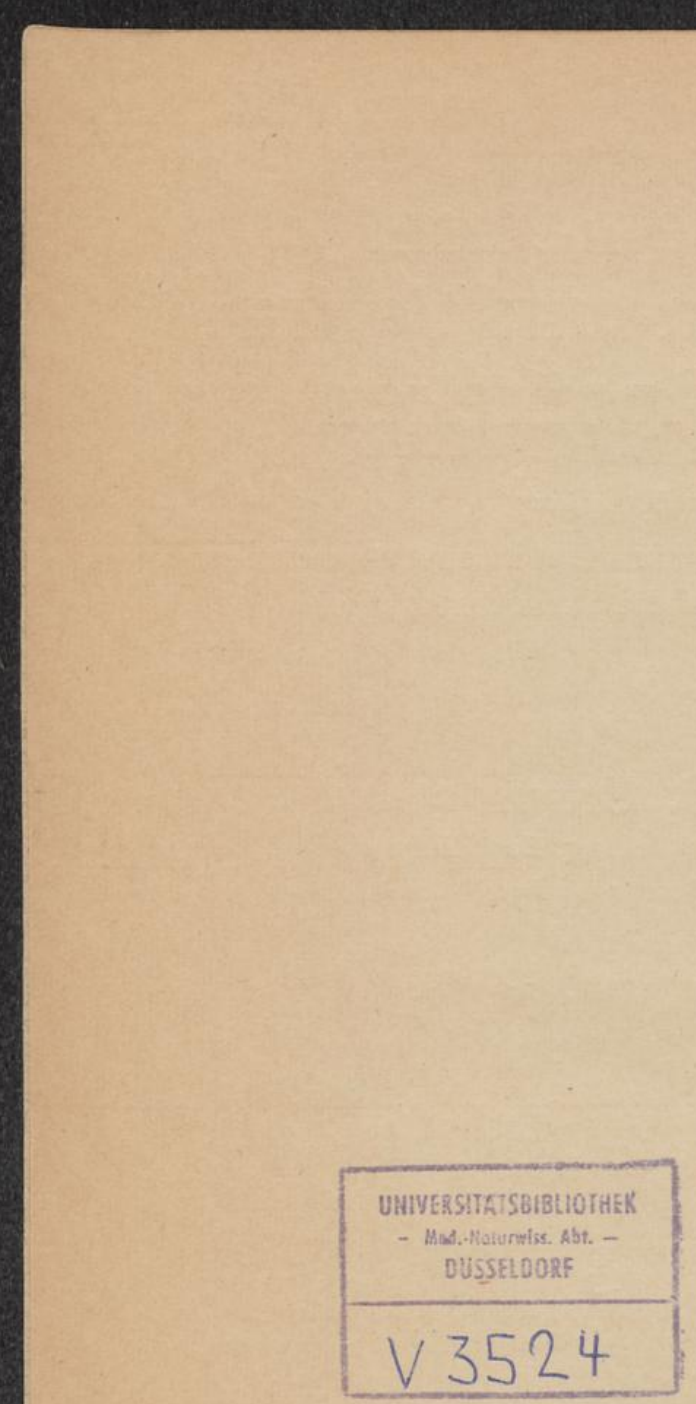




\section{Vorwort zur 1. Auflage.}

Es soll dies Büchlein ein schlichter Ratgeber sein und in unparteiischer Weise beiden Parteien beim Apotheken An- und Verkauf zugute kommen. - Sowohl der junge Anfänger wie auch der ältere, erfahrene Apotheker wird in ihm viel Wissenswertes finden und sich dadurch manchen Kummer und Schaden ersparen.

Einiges wird dem Leser sehr selbstverständlich erscheinen; aber in dem Augenblick, wo es darauf ankommt, vergißt man oft so manches. $\mathrm{Da}$ ist es vorteilhaft, wenn man als guten Freund und Berater stets das Vademecum zur Hand hat.

Leipzig-Schleußig, den 1. Februar 1913.

G. Unruh, Apotheker.

\section{Vorwort zur 2. Auflage.}

Die freundliche Aufnahme, welche das Vademecum im Kreise der Fachgenossen gefunden hat, und viele Worte der Anerkennung, welche mir zugingen, zeigen, wie willkommen ein solcher Ratgeber den Kollegen war und wieviel Nutzen er gestiftet hat.

Verfasser dieses Heftchens hat in seiner Eigenschaft als Taxator von Apothekenwerten und Kommissionär für Apothekenverkäufe viele Apotheken kennen gelernt; seine inzwischen gemachten Erfahrungen sollen der neuen Auflage zugute kommen. So wird diese zweifelsohne gleichfalls willkommene Aufnahme finden und fernerhin Gutes stiften.

Bad Kösen, 1920.

G. Unruh, Apothekenbesitzer.

Beeidigter Taxator für Apothekenwerte. 
Inhaltsverzeichnis.

Einleitung Seite

I. Der Käufer . . . . . . . . . . . . . . 7

II. Der Verkäufer . . . . . . . . . . . . . . 15

III. Der Kaufvertrag . . . . . . . . . . . . . . . 19

IV. Schreiben des Verkäufers an die Regierung zwecks Uebertragung der Konzession . . . . . . . . . . . 25

V. Gesuch eines Käufers um Erteilung der Konzession zur Fortführung der gekauften Apotheke . . . . . . . 25

Anhảng. Anleitung für die Buchführung in einer Apotheke mit Rücksicht auf die Steuer-Deklaration . . . . . 27 


\section{Einleitung.}

Tritt an den jungen Fachgenossen die Zeit heran, sich durch Kauf einer Apotheke ein eignes Heim zu gründen, so wende er sich getrost an einen Kommissionär, zu dem er das meiste Vertrauen hat. Für Käufer wie Verkäufer wird die Tätigkeit eines gewissenhaften, nicht allein auf sein Vorteil bedachten Vermittelers segensreich wirken. Bei mündlicher Verhandlung wird dieser einen Kaufabschluß oft viel schneller zur beiderseitigen Zufriedenheit zustande bringen.

Ein Käufer erwirbt auch wohl eine Apotheke, indem er auf ein Inserat schreibt oder sonstwie mit dem Verkäufer direkt in Verbindung tritt. $\mathrm{Er}$ nimmt in diesem Fall vielleicht einen befreundeten Apotheker zu seiner Unterstützung in Anspruch. Es ist aber sehr die Frage, ob dieser eine derartige Erfahrung besitzt, wie ein Kommissionär, um ihn vor Uebervorteilung zu schützen. Man breche also nicht ohne weiteres den Stab über die Tätigkeit eines Vermittlers; Zehntausende sind oft schon dem Käufer wie Verkäufer durch jenen gerettet worden. Doch sollte man sich nur eines solchen Vermittlers bedienen, der unserem Stande angehört, also selber Apotheker ist.

Hat man sich nun von den Offerten 2 oder 3 Apotheken ausgesucht mit dem Glauben, daß diese den eigenen Wünschen nahe kommen, so schreibe man in einem Briefe dem Verkäufer, ob ein Besuch zur Besichtigung und mündlichen Besprechung ihm genehm sei. Man gebe gleichzeitig einiges nähere über seine eigene Person an, auch Referenzen auf; denn der Verkäufer will nicht an irgend einen Beliebigen sein Geschäft abgeben, sondern einen Nachfolger haben, der ihm gewisse Garantien bietet.

Hat man nun eine zusagende Antwort erhalten, so reise man mit einem Ausweispapier (zu empfehlen ist eine Postausweiskarte mit Photographie) nach dem betreffenden Ort und der Apotheke.

Man ordne vorher seine Geldangelegenheiten, sodaß ev. ein Abschluß sogleich stattfinden kann. Doch können sich manche Herren nicht zu einem sofortigen Kauf entschließen, und ist das in vielen Fällen auch angebracht und zu verstehen. 
Es kaun aber dann kommen, daß ein paar Tage später die Apotheke an einen anderen verkauft ist und man alsdann das Nachsehen hat und verärgert ist, weil man doch selber schließlich gerne die Apotheke gehabt hätte. Zu empfehlen ist auch, sich $10000 \mathrm{Mk}$. bares Geld sicher verpackt einzustedken. Gefällt einem die Apotheke ganz besonders und man will sie gleich kaufen, oder man will in einem anderen Falle um einen Betrag billiger kaufen, dann hat sich dieses, auf den Tisch des Hauses gelegte Bargeld oft als wunderbarer. Helfer erwiesen.

Es taugt nicht, wenn man allzu unentschlossen und ängstlich ist, dem Mutigen gehört die Welt!

Und selbst, wenn die Apotheke als solche den Erwartungen nicht entspricht, so gibt es genug andere Wege, seine Einnahmen zu verbessern und ein anderes Geschäft seiner Apotheke anzugliedern.

Wenn es auch eigentlich im Rahmen dieses Büchlein nicht gehört, so will ich doch einige Fingerzeige dieserhalb geben.

Der Landapotheker im Städtchen mit nur 1 oder 2 Aerzten muß bestrebt sein, sich in seinen Einnahmen unabhängig von diesen zu machen. So wenig es taugt, intim mit einem Arzt in einer kleinen Stadt zu verkehren, so unangenehm ist es natürlich, sich wie Katz und Hund mit diesem zu stehen. Zeigt man dem Arzt aber, daß man durch seine Nebeneinnahmen vollkommen unabhängig von ihm ist, so kommt er einem schon selber. Schließlich schadet er sich am meisten, wenn er den Patienten nichts verschreibt und allerlei Hausmittel verordnet. Wohl jeder Apotheker weiß aus der Praxis, wie das Publikum von solchen Herren spricht. Wie der Großstadtapotheker in seinem Labor pharmaceutische Präparate herstellt und sich in einigen von diesen spezialisiert, so kann das natürlich auch der Kleinstadtapotheker. Jener wird in seinem Labor vielleicht noch Untersuchungen aller Art ausführen und sich betr. dieser mit der Stadtverwaltung und den Aerzten in Verbindung setzen. Nur ein Mittel nach wirklich guter Vorschrift hergestellt und mit geschickter Reklame in den Handel gebracht, wirft bestimmt jährlich paar tausend Mark ab. In Gegenden, in denen Arzneipflanzen viel wachsen, kann man diese durch Kinder sammeln lassen, sie entweder roh verkaufen oder Heilmittel selber daraus herstellen, wie Extrakte, Alkaloide. Auch das Kultivieren von Arzneipflanzen lohnt sich; man pachte sich dazu einige Morgen Land, wenn man es im großen betreiben will. Viele Apotheker in Kleinstädten haben auch die Trichinenschau, oder Agenturen von Lebensversicherungen, Feuerversicherungen, 
Kassenverwaltungen. Dem rührigen und umsichtigen Apotheker in seinem kleinen Geschäft von vielleicht 15000 Mk. Medizinalumsatz bietet sich soviel Gelegenheit, seine Einnahmen zu vergrößern, daß ihm oft der Tag zu kurz wird, um alles schaffen zu können. Er kann sich dafür jährlich aber auch etliche Wochen einen Vertreter leisten und durch schöne Reisen neue Eindrücke sammeln, sodaß er erfrischt und freudig an seine Arbeitsstätte zurückkehrt. Es lohnt sich auch, an Industrielle und größere Güter zwedks Lieferungen heranzutreten. Was andere Firmen liefern können, kann man auch, oft noch preiswerter. Die Molkereien brauchen z. B. viel Schwefelsäure, Güter Karbolineum, Saatbeize, Ungeziefermittel, ein Gut oft für $1000 \mathrm{Mk}$. und mehr.

Der Kleinstadt-Kollege wird in seinem Hause, das er sich nach seinem Geschmack behaglich ausstatten kann, in seinem Garten, in dem er nach Herzenslust schaffen und pflanzen kann, sich heimisch und glücklich fühlen und oft mit keinem Großstadtapotheker tauschen wollen. „Eigner Herd ist Goldes wert", das trifft namentlich bei dem Landapotheker zu. Deshalb rate ich jedem jungen Kollegen, so bald er kann, sich selbständig zu machen und seine gesunde junge Kraft für eigenes Vorwärtskommen zu verwenden. Die Klagen der Landapotheker über ihr Gebundensein, ihre schlechte Lage, werden dem unverständlich sein, der um sich zu schauen versteht und nicht mit den Händen in der Tasche in seiner Offizin steht und auf die paar täglichen Rezepte wartet.

\section{Der Käufer.}

1. Man mache zunächst einen Rundgang durch die Geschäftsräume, Privatwohnung, Hof und Garten, und lasse sich auch die Mietwohnungen zeigen. Man wird sehen, ob am Hause viel auszubessern ist, achte vornehmlich auch auf das Dach. Deshalb rauf bis auf den obersten Boden und runter bis in den Keller, ob dieser nicht feucht ist.

2. Fragen: Wieviel Aerzte sind am Ort und ist bekannt, ob einer verzieht oder die Praxis niederlegen will? Durch einen Arztwechsel kann eine bedeutende Aenderung im Geschäftsumsatz eintreten. - Sind irgendwelche Abmachungen mit den Aerzten getroffen? Ist der Verkehr mit ihnen ein intimer, ev., gehört einer demselben Studenten-Verbande an, wie Verkäufer? 

Dispensiert ein Tierarzt selber oder wieviel Prozente erhält er andernfalls auf seine Ordinationen, und wie ist die Buchung dieser Ausgabe? Wie ist den Aerzten der persönliche Bedarf von Waren aus der Apotheke angerechnet und gebucht worden?

3. Sind größere Lieferungen an Krankenkassen oder Fabriken vorgekommen und unter welchen Bedingungen? welcher Art? Bestehen Abmachungen mit solchen und muß Käufer in die Verträge (durchlesen!) eintreten? Wechseln Lieferungen mit anderen Apotheken? und ist der Betrag der Lieferungen zum Umsatz gezählt oder extra gebucht?

4. Wie groß ist der Umsatz in Brunnen, Wein oder $\mathrm{W}$ aren, die nicht überall gang und gebe in Apotheken sind? (Materialwaren.)

5. Man lasse sich eine Anzahl Rechnungen geben, um sich ein Bild von Art und Menge des Warenbezuges zu machen und merke sich auch die Lieferanten.

6. Erbittet man das Warenbezugsbuch und notiere sich die größeren Posten, auch die Namen der Firmen. Man gebe acht, wie das Buch geführt ist. (Sauberkeit, Akkuratesse.)

7. Das Umsatzbuch. Im Notizbuch, welches man stets zur Hand habe, notiere man sich die Posten der einzelnen Rubriken von den letzten drei oder vier Jahren? - Wieviel Prozente erhalten die Kassen und ist der Betrag im vorliegenden Buche bereits abgezogen? oder extra in der Ausgabe angegeben?

8. Man frage, ob der Verkäufer das Umsatzbuch und Warenbezugsbuch seinem Nachfolger-überlassen wolle. Gesetzlich ist Verkäufer hierzu nicht verpflichtet. Es kann aber ein entsprechender Passus im Kaufvertrage aufgenommen werden. Man sei aber nicht gleich mißtrauisch, wenn Verkäufer die Uebergabe der Bücher nicht wünscht! (Ein Mittelweg, vgl. Kaufverirag.)

9. Verkäufer muß im Kaufvertrage dafür garantieren, daß die angegebenen Zahlen im Umsatz- und Warenbezugsbuch richtig sind; er kann dies natürlich nur derart tun, daß er sagt: Nach bestem Wissen sind die Zahlen richtig, für Rechenfehler kann ich nicht aufkommen.

10. Man lasse sich eine Anzahl Rezepte geben, um sich von der Vershreibweise der Aerzte ein Bild zu machen. Was ist alles zur Rezeptur gerechnet worden? Sera? vom Arzt verordnete Spezialitäten?

Man sehe auch das Rezeptjournal ein, falls ein solches geführt wird. 
11. Würden Sie in Rücksicht auf den Kaufpreis eine Garantie dafür übernehmen, daß innerhalb 5 Jahre keine Neukonzession erteilt wird, die als Konkurrenz in Frage kommt? - Hierauf wird sich wohl selten ein Verkäufer einlassen; denn man kann für das Tun und Lassen der Regierung nicht gut eine Garantie übernehmen. - Aber so: Wieviel würden Sie vom Kaufpreise zurüdkzahlen, wenn innerhalb 3 Jahre eine Konkurrenzapotheke eröffnet werden würde? - Ist auch dies nicht $z u$ erreichen, so begnüge man sich, daß im Kaufvertrage aufgenommen werde: dem Verkäufer ist bis heute nichts zu Ohren gekommen, daß eine Apotheke neu konzessioniert werden soll. - Kann man im eintretenden Falle später dem Verkäufer nachweisen, daß er mit jemand über eine schwebende Neukonzession gesprochen hat, so kann er dann für Schaden haftbar gemacht werden.

12. Man frage nach Nebengeschäften und ob von dem Umsatz derselben etwas zum Apothekenumsatz gezählt ist. (Fleischbeschau, Agenturen, Versand.)

13. Wie würden Sie den Warenbezug vor Uebernahme des Geschäfts regeln? (Ist hierüber nichts ausgemacht, so kann es dem Käufer passieren, daß er bei Uebernahme des Geschäfts ein ausgeräubertes Warenlager vorfindet.) Man sage also: Der Warenbezug in den letzten 3 Monaten vor Uebergabe des Geschäfts soll den angegebenen Warenunkosten entsprechen. Betragen diese z. B. 12000 Mark pro anno, so soll der Verkäufer im letzten Vierteljahr auf Verlangen einen Warenund Utensilienbezug von 2500 Mark (also etwas weniger) durch Rechnungen nachweisen können. Man begnüge sich nicht mit dem beliebten Passus: Warenbezug erfolgt wie üblich.

14. Man lasse sich die Revisionsprotokolle geben und frage, ob die Apotheke in einem revisionsmäßigen Zustande übergeben werde. Ist dies nicht zu erreichen, so begnüge man sich damit. Die Apotheke wird in dem Zustand übergeben, den sie bei der letzten Revision hatte.

Sieht ein Haus und Geschäft unordentlich und trödelig aus, so braucht man sich deshalb keineswegs vom Kauf abschrecken lassen. Mit der Uebernahme erfolgt dann ein großes Reinemachen und ein neuer Aufbau des Geschäfts. Das Publikum merkt bald, wieviel sauberer und vorteilhafter jetzt alles aussieht wie früher. Das wird für die Hebung der Apotheke und das Ansehen des neuen Besitzers nur günstig sein.

15. Wie wird das Gehilfen- und Elevenzimmer übergeben? 
Die Einrichtung des ersteren muß gesełzlich dem Käufer verbleiben, die des letzteren nicht. Man nehme im Kaufvertrage entsprechendes auf.

16. Welche Abgaben und Lasten ruhen auf dem Geschäft und Grundstück?

Es sind oft nicht unbedeutende Abgaben aus alten verbrieften Rechten zu leisten.

17. Man bedinge sich aus, daß Verkäufer am Ort und im Umkreis bis 5 Meilen kein Geschäft eröffne, das als Konkurrenzgeschäft (Drogerie) in Frage kommt.

18. Eine etwa vorhandene Kontrollkasse muß dem Käufer verbleiben. Die Vorschriften für eigene Spezialitäten hat Verkäufer seinem Nachfolger zu übergeben, ebenso die für die Apoiheke nötigen wissenschaftlichen $\mathrm{B}$ ücher und $\mathrm{Hilfs}$ bücher (z. B. Hagers Kommentar, Helfenberger Manual). Auch ein Prospisil-Apparat muß in der Apotheke bleiben (ev. Kontoreinrichtung), man nehme alles diesbezügliche im Kaufvertrag auf.

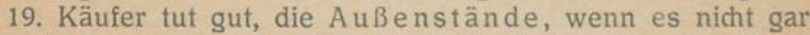
zu große Summen sind, mit 5 bis $10 \%$ Abschreibung zu übernehmen. Die Summe ist dem Verkäufer alsdann bei der Uebernahme in bar auszuzahlen.

20. Steuern und Abgaben beim Besitzwechsel. Das neue Grunderwerbssteuergesetz unterwirft den Uebergang von inländischen Grundstücken und von solchen Berechtigungen, auf welche die Vorschriften des bürgerlichen Rechtes über Grundstücke Anwendung finden, einer Steuer zugunsten des Reiches. Diese Abgabe ist mit 4 v. H. belastet, von welchem Ertrag das Reich die Hälfte erhält. Ueber die Verwendung des anderen Teiles, insbesondere über seine völlige oder teilweise Ueberweisung an die Gemeinden, treffen die Länder Bestimmung.

Der Mehrbelastung stehen eine Reihe von Vorteilen in Vergleich zum bisherigen Rechtsstand gegenüber, deren wichtigste die Ersetzung der bisherigen verschiedenen, denselben Rechtsvorgang betreffenden Abgaben durch eine einheitliche zu veranlagende und $\mathrm{zu}$ erhebende Steuer ist. (K. v. Lewinski: Die Steuergesetze 1919.)

Mit dem Inkrafttreten dieses Gesetzes vom 1. Oktober 1919 sind fortgefallen: der Reichsumsatzstempel, der Landesmobilienstempel, die Kreis- und Gemeindeumsatzsieuer. Es bleiben also bestehen: der Landesmoblienstempel und der Landeskonzessionsstempel (in Preußen $1 / 2{ }^{0}, 0$ ), doch ist zu beachten, daß nach der neuen Rechtssprechung der Apothekenwert unter Umständen ein den Grundstückswert erhöhendes Moment 
ifer ıufGeterim n 1fer hat die her ein torauf. gar errereue inauf ndhes. das ren rering. in ichben zu ski:

darstellt, soda $B$ also der Grundstückswert mit Rücksicht auf die in dem Hause betriebene Apotheke höher angenommen werden kann, als es sonst der Fall wäre.

Es würde hier zu weit führen, alles diese wichtige Frage betreffende auseinander zu setzen. lic gebe deshalb folgende Quellen zum Nachlesen an: Pharmaceutische Zeitung 1913: Nr. 14; 1915: Nr. 28; 1916: Nr. 62; 1917: Nr. 91; 1919: Nr. 76.

Für die Anwendung des Grunderwerbsteuergesetzes auf die verschiedenen Arten Apothekenberechtigungen gilt in Zukunft alles das, was bisher ũber den Reichsumsatzstempel gesagt worden ist, so z. B. in den Preuß. Apothekengesetzen von Böttger-Urban und in den Artikeln der Pharm. Ztg. 1912 Nr. 55. - Von den neuen Steuergesetzen dürfte nur die Kriegsabgabe vom Vermögenszuwachs zu erwähnen sein, worüber sich in Pharm. Ztg. 1919 Nr. 76 ein Kommentar befindet.

21. Hat man nun alles durchgesprochen und die Ueberzeugung gewonnen, daß das Geschäft einem zusagt, so mache man noch einmal einen Rundgang und halte dabei die Augen offen. Man sei in allem aber nicht zu kleinlich und gebe vor allem nicht zu sehr seiner Frau Gehör, obwohl es durchaus zu emptehlen ist, daß auch die Frau vorher ihren zukünftigen Wirkungskreis kennen lernt. Aber geracie die Frauen (und Schwiegerväier!) sind oft in vielem so nörglich, daß die Verkaufsverhandlungen erschwert und unmöglich werden.

22. Ist man sich nun über alles soweit einig und hat sich im Notizbuch entsprechende Vermerke gemacht (doch nur das, was im Kaufvertrag bedingt ist, hat Gültigkeit, mündliche Abmachungen und selbst schriftliche Aufzeichnungen sind fast nie mit Erfolg gerichtlich anfechtbar!), so suche man zu erreichen, daß Verkäufer einem das Geschäft ein paar Tage ,an der Hand läßt“.

Während dieser Zeit erkundigt $m$ an sich in diskreter Weise nach Verschiedenem; etwa nach dem Charakter des Verkäufers, ob er beliebt im Ort, wie die gesellschaftlichen Verhältnisse sind usw. - Man wird ja auch erfahren, wieviel der Verkäufer seinerzeit für das Geschäft bezahlt hat. Er wird in allen Fälien eine mehr oder weniger große Summe an dem Geschäft verdienen wollen. Jedem Käufer muß ein Geschäft, das vorwärts schreitet, lieber sein, als eins, das stehen bleibt oder zurück geht. Und der Käufer selber hofft doch auch, daß er es nach etlichen Jahren weiter gebracht hat. Warum soll man es dem Verkäufer nicht gönnen, daß er - vermöge seiner 
Tüchtigkeit oder zufolge sonstiger Umstände, denen das Geschäft einen gestiegenen Umsatz verdankt ... einen Verdienst am Verkauf hat!

Jeder Verkäufer verlangt Diskretion im Orte und jeder anständige Käufer wird diese wahren. Er kann sich natürlich nach diesem oder jenem in unauffälliger Weise erkundigen, das wird ihm der Verkäufer durchaus nicht verargen.

Mir ist jedoch ein Fall bekannt geworden, in dem ein Käufer die genaueste Information des Vermittlers einem ihm gänzlich fremden Herrn in der Kleinstadt gab und sagte: lesen Sie das bitte mal durch, ob das so richtig ist. Ueber solche bodenlose Unverschämtheit ist man sprachlos.

Es wird in einem kleinen Ort die Absicht, zu verkaufen, übrigens nicht lange geheim bleiben. Deshalb ist es am besten, wenn innerhalb 8 Tagen die ganze Sache erledigt ist, was sich wohl machen läßt.

23. Manche Käufer erkundigen sich bei einem Auskunftsbüro nach dem Geschäft, welches sie zu kaufen beabsichtigen. - Diese Auskünfte sind sehr oft falsch und gehässig, so daß man eigentlich nichts auf dieselben geben kann, namentlich in kleineren Städten. In diesen ist ein Kaufmann oder ein kleiner Handwerker meistens ,,Vertrauensmann“ des Büros. Jenachdem nun der Angefragte bei dem „Vertrauensmann" kauft oder arbeiten läßt, fällt nun auch die Auskunft aus. Mancher Käufer, der glaubte, eine Auskunft von "einwandfreier Stelle" zu erhalten, ist dadurch schon oft geschädigt worden, indem ihm ein gutes Geschäft, das er sonst gekauft hätte, entgangen ist. Also man lasse sich durch eine schlechte Auskunft nicht irre machen.

24. Als weitere Fragen, die dem einen mehr, dem anderen weniger Interesse bieten, kann man noch stellen und gleich im Notizbuch notieren:

Wie hoch war der Umsatz früherer Jahre?

Wieviel Rezepte haben Sie täglich?

Wie hoch geben Sie den Netto-Reingewinn aus Ihrem Geschäft an?

Wie hoch ist das Grundstück in der Feuertaxe?

Wie ist das Verhältnis zu Ihren Nachbarn?

Wer hat den Zaun oder die Mauer des Nachbargrundstücks Instand $\mathrm{zu}$ halten?

Wieviel kostet die Instandhaltung des Gartens und wie gro $B$ ist der Ertrag aus demselben? 
Wieviel Seelen kommen auf die Umgegend?

Wie hoch sind die Steuern am Orte?

Wieviel kosten elektr. Licht, Gas und Wasser?

Wie sind die Schulverhältnisse?

Wie oft schreiben Sie Rechnungen?

Wieviel Ausfälle haben Sie gehabt?

Wieviel Drogisten sind im Orte oder Umgegend.

Ist man genötigt einen größeren Verkehrskreis zu unterhalten und größere Gesellschaften zu geben? Konto).

25. Die Ausgaben des Geschäfts (cfr. Anhang Unkosten-

Diese setzen sich zusammen:

Waren und Utensilien nach Abzug der Returen.

Gehalt und Lohn. Kost. Weihnachtsgeschenke.

Feuerung, Licht und Wasser für das Geschäft.

Steuern und Abgaben.

Versicherungen, (Feuer-, Haft-, Unfall-, Kranken- und Invaliden-Versicherung.)

Fracht und Porto, auch Briefporto, Schreibwaren.

Telephon und die Ferngespräche.

Rabatte und Verluste.

Reparaturen. Erhaltung und Ergänzung des Inventars und des Grundstückes.

Diverse kleine Ausgaben. (Reklame, Zeitschriften. Beiträge zu Vereinen, Verbänden.)

Zinsen.

Für Waren und Utensilien kann man rechnen:

In einem Geschäft mit $2 / 3$ Rezeptur $30 \%$.

In einem Geschäft mit $1 / 2$ Rezeptur $35 \%$.

In einem Geschäft mit $1 / 3$ Rezeptur $45 \%$.

Eine genaue Formel läßt sich darüber aber nicht geben; es kommt natürlich auf die jeweiligen Verhältnisse an.

In früheren Jahren bezahlte man das $7-8$ fache des Umsatzes für eine Apotheke. In den letzten Jahren ist es bräuchlich, nach dem Reingewinn eine Apotheke zu kaufen, das einzig richtige Verfahren. Es bleibt dabei jedem Käufer überlassen, einen wie hohen Reingewinn er verlangt, danach kann er den Preis bewilligen oder nicht. In früheren Jahren verlangte ich bei einer Apotheke von 20-40000 Mark Umsatz einen Reingewinn (nach ganzer Verzinsung des Kaufpreises und bei Haltung des nötigen Personals,) von 5-9000 Mark. Jetzt, nach dem Kriege in der Zeit der Teuerung, da dies 
Büchlein erscheint, verlange ich ungefähr das Doppelte des Reingewinns, unter Zugrundelegung des Durchschnittsumsatzes (4080000 Mark) der beiden letzten Jahre. In diesem Sinne habe ich die Wertschätzungen der Apotheken ausgeführt und auch viele Verkäufe vollzogen, und zwar im vollsten Einverständnis beider Parteien.

26. Oft wird aus Mieten ein nicht unbedeutender Betrag eingenommen und das Geschäft entsprechend hoch bezahlt. Man sei nun, was dies anlangt, recht vorsichtig. Zunächst lasse man sich die Mietkontrakte zeigen und prüfe, wie lange diese laufen und frage, ob ev. ein Mieter ausziehen will. Man lasse sich vom Verkäufer die ausdrüdkliche Versicherung geben, daß die im Mietkontrakt stehende Summe auch vom Mieter wirklich bezahlt ist und nehme möglichst einen entsprechenden Passus im Kaufvertrage auf. Es ist schon vorgekommen, daß vom Mieter statt des im Mietkontrakt stehenden Mietzinses von angenommen 2000 Mark in Wirklichkeit nur 500 Mark gezahlt sind; und zwar im stillschweigenden Einverständnis mit dem Vermieter.

27. Die Hypotheken.

Das ist nun ein recht wichtiges Kapitel, das man nicht genug beachten kann. Es gibt Zeiten, in denen sehr schwer Geld auf Hypothek zu bekommen ist und Käufer kann da in ein rechtes Dilemma kommen, wenn ihm eine Hypothek gekündigt wird. Man notiere sich genau den Stand und Zinsfuß der Hypotheken und auch den Wohnort der Gläubiger. Stehen die Hypotheken des zu erwerbenden Besitzes nur noch $1-2$ Jahre fest, so suche man sich vorher mit den Gläubigern in Verbindung zu setzen, um eine längere Kündigungsdauer zu erhalten, und bediene sich dabei der Hilfe des Verkäufers.

Ein recht mißliches Ding sind jährliche $\mathrm{Abzahlungen;}$ darauf lasse man sich, wenn irgend möglich, nicht ein. Jedenfalls lege man diese Abzahlungen sonst im Kaufvertrage ganz bestimmt fest.

Die Resthypothek des Veräußerers bleibt meistens auf 8-10 Jahre zu $5 \%$ fest stehen (mitunter auch $4 \frac{1}{2} \%$ ). Einen je längeren Termin der Käufer erzielen kann, desto besser ist es natürlich für ihn.

Man lasse sich vom Amtsgericht einen Grundbucha uszug geben (ca. 1.50 Mark) und prüfe genau, ob die vom Verkäufer gemachten Angaberi betr. der Hypotheken stimmen. - Das Grundstück kann vom Verkäufer auch noch nach Verkaufsabschluß mit Hypotheken belastet werden; daher muß 
Verkäufer die Garantie übernehmen, daß das Grundstüdk bei der Auflassung nicht mehr belastet ist, als im Kaufvertrag angegeben. Verkäufer muß auch dafür garantieren, daß die von ihm gemachten Angaben betr. Zinsfuß und Kündigungstermin der Hypotheken richtig sind.

28. Der Käufer muß bei dem Amtsgericht nach der Auflassung seine Firma eintragen lassen, nachdem Verkäufer diese gelöscht hat. - Wie der Name der Firma sein soll steht ganz im Belieben des Käufers. Er muß persönlich im Amtsgericht seine Firma zeichnen, auf schriftlichem Wege läßt sich das nicht erledigen.

29. Der Käufer vergesse nicht, daß er genügend Betrie bskapital zur Hand habe und nicht bald nach der Uebernahme in Geldverlegenheit komme.

30. Zum Schluß soll nun noch gesagt sein, daß der Käufer nicht alle diese Fragen schriftlich vom Verkäufer verlange; er würde von diesem darauf auch keine Antwort erhalten.

\section{Der Verkäufer.}

Will jemand seine Apotheke verkaufen, so sei er vor allem darauf bedacht, daß es möglichst schnell geschehe, innerhalb 8 Tagen, wie ich schon im vorigen Abschnitt sagte. Sonst ist es bald mit der Diskretion vorbei, und man wird auf der Straße mit erstauntem und bedauerndem Lächeln von den guten Nachbarn angehalten, warum man denn aus dem schönen Städtchen fort wolle.

Um zu sehen, ob der Preis, den man für sein Geschäft zu fordern sich vorgenommen hat, den Verhältnissen entspricht, lasse man sich eine Wertschätzung machen und erbittet einen Kommissionär zur Besprechung zu sich.

Dadurch erhält ein Verkäufer oft paarmal 10000 Mark mehr für seine Apotheke, als er sich gedacht hat; andererseits wird der herbeigerufene Beistand von einem zu hohen Preise abraten, um nicht den Verkauf unnötig in die Länge zu ziehen, der dann schließlich doch zu einem geringeren Preise stattfindet, nachdem die Apotheke durch das lange Feilhalten in Miskredit geraten ist.

Mancher Apothekenbesitzer versucht auch auf eigene Faust seine Apotheke zu verkaufen ohne jemand um Rat zu fragen, zumal, wenn ein Kaufliebhaber ihm andauernd darum angeht. Ganz abgesehen von der ungeheuren Schreiberei, welche jenes Verfahren mitsichbringt, dürfte dasselbe aus eingangs erwähnten Gründen zu verwerfen sein. 

1. Meldet sich schriftlich ein Käufer und stellt er noch so kuriose Fragen, so weise man ihn ohne weiteres nicht ab, sondern antworte ihm kurz, man bäte um seinen Besuch, da sich mündlich alles besser abwickeln ließe. Denn es haben schon oft gerade solche Käufer das Geschäft gekauft, von denen man es nach dem schriftlich Vorraufgegangenen am allerwenigsten erwartet hätte.

2. Erhält man den Besuch eines Käufers, so lobe man nicht mit großem Wortschwall dies und jenes und versuche alles im günstigsten Lichte hinzustellen, oder seine eigne Tüchtigkeit zu preisen; gerade im Gegentei', man mache den Käufer auf diese oder jene Uebelstände aufmerksam. Dadurch kann man nur an Vertrauen gewinnen.

3. Ist Käufer zur Zeit noch Besitzer einer Apotheke, so stelle man die Bedingung, daß derselbe sich zu einem Reugeld von 10000 Mark verpflichte, wenn er bis zum Termin der Uebernahme des neuen Geschäftes seine bisherige Apotheke nicht verkauft hat. - Angenommen, der Kaufvertrag ist gemacht, aber der Käufer ist seine Apotheke bis zum festgesetzten Termin nicht losgeworden, so kann man ihn nicht mit Erfolg zwingen, das erkaufte Geschäft zu übernehmen. Denn der Käufer weigert sich nicht, die Apotheke zu übernehmen, kommt auch bei der Regierung um die Konzession ein; aber diese kann ihm nicht erteilt werden, da er ja noch eine Apo' heke besitzt. Im Kaufvertrage heißt es aber, daß derselbe nur im Falle einer Konzessionsbewilligung Gültigkeit habe.

Ob Käufer zurzeit Privileg oder Konzession besitzt, ob er Privileg oder Konzession kaufen will - immer bedinge man sich vor Kaufabschluß aus, daß Käufer zunächst seine alte Apotheke verkaufe oder sich zu einem Reugeld verpflichte.

4. Ist Käufer Besitzer gewesen und jetzt frei, so ist die Sache einfacher. Man kann sich aber immerhin bei seinem Nachfolger erkundigen. Wenn sein Geschäft einen entsprechenden Umsatz hatte, kann man annehmen, daß er auch eine entsprechende eigne Anzahlung verfügt.

Gehört der Ehefrau des Käufers ein Teil der Anzahlung, so muß jene den Kaufvertrag mitunterschreiben. Dieses ist sehr zu beachten.

Ist Käufer aber ein noch junger unverheirateter Kollege und leben seine Eltern noch, so ist Vorsicht am Platze. Der Betreffende besitzt in diesem Falle nicht selber die Anzahlung, sondern erhält sie von seinen Eltern, Schwiegereltern oder Verwandten. Man schließe in einem solchen Falle nur

eil tel Si od $\mathrm{K}$ $\mathrm{m}$ in tus od Kà sch 
loch $a b$, da hon nan iten

eke

cht, "er-

lolg

der

imt

ese

itzt.

ner

ob

ige

alte

ist

em

en-

nt-

einen Kaufvertrag $a b$, wenn Käufer sich verpflichtet, bei Unterzeichnung des Vertrages 10000 Mark bei einer Bank zur Sicherung des Vertrages zu hinterlegen, oder wenn der Vater oder ein Verwandter, den man für vermögend halten kann, den Kaufvertrag mit unterschreibt. - Von diesen Vorsichts maßregeln gehe man auf keinen Fall ab!

5. Man bedinge sich den Passus aus: das Geschäft wird in dem Zustande verkauft, in dem es sich befindet. Eventuell füge man hinzu: Dafür, daß in dem Geschäft vielleicht dies oder jenes fehlt oder zu erneuern ist, zahlt Verkäufer dem Käufer eine Summe.

6. Für einen bestimmten Umsatz oder Ertrag des Geschäftes für die Zukunft wird keine Garantie übernommen. Es kann nur dafür garantiert werden, daß die angegebenen Zahlen nach bestem Wissen richtig sind.

7. Man sage im Kaufvertrage auch, daß Käufer sich vergewissert habe, welcher Art Waren in dem Geschäft geführt wurden. Es ist einmal ein Kauf rückgängig geworden, als Käufer später feststellte, daß sein Vorgänger Karbolineum, Viehsalz usw. verkauft hatte.

8. Ein sehr wichtiger Passus im Kaufvertrage ist der: über das Verhältnis des Umsatzes in der Rezeptur zu dem Umsatz im Handverkauf herrscht Einverständnis. Es wird dieserhalb vom Verkäufer keine Garantie übernommen.

9. Ferner sage man: Die Rezepte sind nach bestem Wissen taxiert; sind in der Taxe Fehler vorgekommen, so verzichtet Käufer, dieserhalb Ansprüche betr. des Preises des Kaufobjektes geltend zu machen.

Ein Rezeptjournal braucht in manchen Staaten nicht geführt zu werden.

10. Käufer muß sich verpflichten, alle Schritte bei der Regierung zu tun, welche zur Erlangung der Konzession erforderlich sind und jene ev. durch alle Instanzen auf seine Kosten betreiben. - Sollte er sie nicht erhalten, so hat er sämtliche Kosten, welche seine Kaufsverhandlungen hervorgerufen haben, zu tragen.

11. Eine Konzessionsverweigerung kann nur stattfinden, wenn Käufer ehenrührig vorbestraft ist, oder als früherer Besitzer durch schlechte Geschäftsführung bereits mit einer Regierung in Konflikt geraten war und vielleicht Polizeistrafen gehabt hat. Hat Käufer vorher eine Drogerie besessen, so 
liegt der Verdacht nahe, daß einmal eine Polizeistrafe vorgekommen. - Man suche sich zu vergewissern, daß vorstehendes beim Käufer nicht zutrifft.

12. Ist ein Nebengeschäft vorhanden, so nehme man alle Abmachungen diesbezüglich nicht im Kaufvertrage auf, sondern mache einen Nebenvertrag. Dadurch nimmt man der Regierung die Handhabe, Schwierigkeiten betr. der Konzessionserteilung zu machen.

13. Zu manchem Grundstück gehören Ländereien, die einen Ertrag bringen. Man sage im Kaufvertrage, daß für Flächeninhalt und Ertrag dieser Ländereien keine Garantie übernommen werde. Ebenso nicht für Mietserträge.

14. Man nehme ohne weiteres kein Papier oder keine Hypothek in Zahlung, ohne sich vorher über den Kursstand oder die Sicherheit orientiert zu haben.

15. Käufer soll verpflichtet sein, die Verträge zu übernehmen, die Verkäufer mit den Angestellten des Geschäfts geschlossen hat.

16. Verkäufer kann bei der Regierung erst die Abtretung seiner Konzession an den Käufer vornehmen, nachdem letzterer die Anzahlung geleistet hat. Denn die Regierung erteilt die Konzession nicht bedingt, sondern unbedingt. (Das soll heißen, die Regierung sagt nicht: im Falle Sie ihren Kaufvertrao erfüllen, erhalten Sie die Konzession, sonst nicht; sie sagt: Wir erteilen Ihnen die Konzession. Ihr ist es also gleichgültig, ob Käufer den Vertrag erfüllt oder nicht.) Sonst kann es sein, daß Verkäufer am Tage der Uebergabe seine Konzession los ist, aber keine Anzahlung in Händen hat.

Es kommt aber auch vor, daß die Regierung dem Verkäufer mitteilt: Sofern Käufer seine in dem Kaufvertrag festgesetzten Verpflichtungen erfüllt, ersuche ich Sie, die Ihnen erteilte Konzession an mich zurück zu geben. verfährt.

Sicher geht man jedoch, wenn man wie zuerst angegeben

17.Wichtig ist, daß die dem Verkäufer verbleibende Resthypothek sich unmittelbar an die vorhergehende anschließe.

18. Die $\S \S 415-419$ des $B G B$ (bitte durchlesen) sind für den Verkäufer wichtig. Danach braucht er von seinen Hypothekengläubigern nicht aus der Schuldhaft entlassen zu werden. Er muß nach erfolgter Auflassung seinen Hypothekengläubigern von der Besitzveränderung Mitteilung machen. Erfolgt von den Gläubigern binnen 6. Monaten kein Einspruch, so 
Verfestn er-

jeben

restließe. d für ypoin zu ekenErdh, so

ist von ihnen die Schuldübernahme eingegangen worden. Hiervon muß er alsdann seinen Nachfolger benachrichtigen.

Ein Einspruch kann natürlich nur von solchen Hypothekenbesitzern erfolgen, deren Hypotheken nicht auf bestimmte Zeit festgelegt sind.

19. Nach erfolgter Auflassung muß Verkäufer seine Firma beim Amtsgericht löschen lassen. - Die Uebernahme erfolge möglichst bald nach Kaufabschluß. Liegt ein längerer Zeitraum dazwischen, so ist man von mancherlei Zufälligkeiten abhängig. Z. B. kann sich die Vermögenslage des Käufers verschieben, er kann sterben usw. -

Man verkaufe sein Geschäft nur durch einen notariellen Vertrag.

Die $\S \S 10,11,12$ sind bei Privilegien gegenstandslos.

20. Käufer muß die Apothekenkonzession auf dem von ihm gekauften Grundstücke betreiben und hierzu auch seinen ev. Nachfolger verpflichten. Er darf die Konzession auch nicht der Regierung zur Verfügung stellen.

21. Zum Schluß soll nun noch gesagt sein, daß sich in diesen beiden Abschnitten vieles schlimmer liest, als es in Wirklichkeit ist. Parteien, die einander nicht übervorteilen wollen und sich das Leben nicht gegenseitig schwer machen wollen, brauchen nicht so vielerlei im Kaufvertrage aufnehmen. Haben Käufer und Verkäufer gar keine Beziehungen zueinander, so ist es immerhin gut, man sichert sich nach allen Richtungen hin, damit später keine Meinungsverschiedenheiten entstehen.

\section{Der Kaufvertrag.}

Ein Kaufvertrag kann beim Amtsgericht oder beim Notar gemacht werden. Es ist aber dringend $\mathrm{zu}$ empfehlen, einen solchen Vertrag nur notariell zu schließen und die geringen Mehrkosten nicht zu scheuen. Der Notar hat die Interessen beider Parteien wahrzunehmen.

Bevor man zum Notar geht, muß man sich natürlich über die wichtigsten Punkte geeinigt haben.

Ich lasse nun einen vollständigen Kaufvertrag einer verkäuflichen Konzession folgen, der als Richtschnur bei Kaufabschlüssen dienen kann. Mehrfach habe ich schon gefunden, daß einem Notar dieserart Kaufverträge nicht geläufig waren. 

Es ist in diesem Kaufvertrage im Gegensatz zu den vorhergehenden beiden Abschnitten nicht alles aufgenommen, was zum Vorteil des Käufers und nicht alles, was zum Vorteil des Verkäufers erscheint.

Jede Partei muß sich selber ihr Teil zusammen suchen.

\section{Kaufvertrag.}

Stettin, den 8. Januar 1912.

Von mir, dem Königlichen Notar Justizrat Victor Schneider zu Stettin erschienen

1. als Verkäufer Herr Apotheker E. aus Falkenburg,

2. als Käufer Herr Apotheker K. aus Neustadt, ersterer mir von Person bekannt, letzterer mir durch den ad 1 Genannten vorgestellt.

Dieselben ersuchten mich um die Beurkundung eines

$$
\text { Kaufvertrages }
$$

und erklärten folgendes:

§ 1. Der vorgenannte Verkäufer E. verkauft das ihm gehörende, in Falkenburg unter der Hausnummer 56 in der Breitenstraße gelegene Apothekengrundstück, eingetragen im Grundbuch von Falkenburg Band II, Blatt 144, mit

1. dem gesamten zur Einrichtung der Apotheke dienenden beweglichen Inventar und den Warenvorräten.

auf

und

2. der Firma Adlerapotheke E., Falkenburg,

3. der erwerblichen und veräußerlichen Konzession zum Betriebe der Apotheke in Falkenburg

an den vorgenannten Käufer K. zu dem verabredeten Preise von 170000 Mark (einhundertsiebzigtausend Mark).

Von diesem Kaufpreis entfällt der Teilbetrag von

a) 25000 Mark auf das verkaufte Grundstück mit Gebäuden,

b) 20000 Mark auf das bewegliche Inventar und die Warenvorräte, welche zum unmittelbarem Gebrauche in dem Gewerbe oder zur Wiederveräußerung in derselben Beschaffenheit oder nach vorheriger Bearbeitung oder Verarbeitung dienen sollen, oder auch zum Teil in dem Betriebe des Veräußerers hergestellt sind, mit der Maßgabe, daß hiervon wiederum auf das Inventar der Teilbetrag von 5000 Mark fällt, 
her-

was

des

n.

1912.

eider

sterer ad 1

n ge-

1 der

in im

enden

zum

Preise

iuden;

laren-

dem

n Be-

oder

dem

t der

ar der

c) 125000 Mark auf den Verzicht betreffend die Konzession zum Apothekenbetriebe als vereinbarte, dafür zu zahlende Vergütung *).

Hiernach beträgt der Gesamtpreis, welchen der Käufer zu zahlen hat, 170000 Mark.

§ 2. Dieser Preis wird wie folgt berichtigt.

Käufer zahlt 40000 Mark am 1. April 1912 und zwar Zug um Zug gegen Auflassung und Uebergabe des Grundstückes und Geschäfts bar.

Käufer übernimmt in Anrechnung auf den Kaufpreis die auf dem Grundstück lastenden Hypotheken des

Herrn M. in Leipzig von 28000 Mark (achtundzwanzigtausend Mark), des

Herrn A. in Liegnitz von 57000 Mark, des

Herrn C. in Hamburg mit 15000 Mark

und zwar sämtliche Hypotheken mit den Zinsen vom 1. April 1912 an.

\$ 3. Der verbleibende Rest des Kaufgeldes im Betrage von 30000 Mark (dreißigtausend Mark) wird dem Käufer gestundet. Dieses Restkaufgeld soll vom 1. April 1912 ab mit jährlich $5 \%$ in halbjährlichen, am 1. April und 1. Oktober fälligen Raten verzinst und nach 6 monatlicher Kündigung zurückgezahit werden. Bei pünktlicher, nicht sieben Tage übersteigender Zinszahlung, soll das Geld bis 1. April 1922 unkündbar sein.

$\S$ 4. Der Verkäufer ist berechtigt, die sofortige Zahlung des Restkaufgeldes nebst den etwa rückständigen und laufenden Zinsen ohne vorherige Kündigung $\mathrm{zu}$ verlangen, wenn Käufer

1. die Zahlungen einstellt oder die mitverpfändeten Gebäude nicht mindestens mit 20000 Mark versichert hält, oder die Versicherungsprämie nicht rechtzeitig oder nicht vollständig bezahlt, in welchem Falle der Verkäufer auch berechtigt sein soll, die Prämienbeträge für den Käufer zu bezahlen und vom Käufer wieder einzuziehen, oder auf Verlangen des Verkäufers die letzte Quittung über die bezahlten Versicherungsbeträge nicht ungesäumt vorgelegt wird oder

2. mit den Zinszahlungen länger als sieben Tage im Rückstande bleibt oder

3. wenn die Zwangsversteigerung des verpfändeten Grundbesitzes oder eines Teils desselben angeordnet ist oder

*) Man hüte sich, den Kundschaftswert extra anzugeben! 


\section{$-22-$}

4. wenn die Apotheke ohne das Grundstück oder das Grundstück ohne die Apotheke verkauft wird.

Solange diese Bedingungen innegehalten werden, soll das Restkaufgeld nicht vor dem 1. April 1922 kündbar sein.

$\S 5$. Käufer unterwirft sich wegen der in diesem Vertrage vorkommenden Verpflichtungen der sofortigen Zwangsvollstreckung in der Weise, dạ die Zwangsvollstreckung aus der Urkunde auch gegen den jeweiligen Eigentümer des Grundstückes und eine Beschränkung der Zwangsvollstreckung nur in den Fällen des $\$ 775 \mathrm{ZPO}$. zulässig sein soll und beantragt, der Ausfertigung dieser Urkunde die Vollstreckungsklausel hinzuzufügen.

§ 6. Die sämtlichen Bestimmungen des Vertrages finden auf die beiderseitigen Rechtsnachfolger Anwendung.

$\$ 7$. Der Käufer beantragt und bewilligt wegen des Restkaufgeldes von 30000 Mark nebst den genannten Bedingungen die Eintragung einer Hypothek an dem erkauften, eingangs näher bezeichneten Grundbesitze, sowie die Unterwerfungsklausel in das Grundbuch, ferner die Ausfertigung eines Hypothekenbriefes und die Aushändigung desselben seitens des Grundbuchamtes an den Verkäufer.

Die bestellte Hypothek soll sich unmittelbar an die vorhergehende anschließen.

Der Käufer bewilligt und beantragt ferner die Ausstellung eines Hypothekengarantiescheines bei den betreffenden Feuerversicherungsgesellschaften und ermächtigt den Verkäufer, diese Ausstellung auf seine Kosten zu bewirken. Der Käufer tritt in die mit der Preuß. Versicherungs-Gesellschaft zu Stettin und mit der Elberfelder Feuerversicherungsgesellschaft geschlossenen Verträge mit dem 1. April 1912 ein.

Der Käufer verzichtet auf die Vorlegung des Hypothekenbriefes bei der Mahnung, der Kündigung sowie Geltendmachung der Hypothek.

§ 8. Der Verkäufer soll verpflichtet sein, gegen Befriedigung seiner Ansprüche nach Wahl des Eigentümers die Löschung oder Abtragung der Hypothek ohne Gewährleistung auf Kosten des Eigentümers zu bewilligen. Wenn durch vorerwähnte Abzahlung die Hypothek zum Teil als Eigentümerhypothek vom Käufer erworben wird, so darf derselbe nur in der Weise darüber verfügen, daß die Resthypothek des Verkäufers den Vorrang erhält und ist Verkäufer auch nur mit dieser Maßgabe verpflichtet, auf Verlangen des Käufers die Teilhypothek abzutreten. 
Dieses Vorzugsrecht des Verkäufers ist auf Antrag des Verkäufers durch Eintragung einer Vermerkung in das Grundbuch zu sichern, deren Eintragung der Käufer bewilligt.

§ 9. Die mit dem Kaufgegenstande verbundenen Rechte und Nutzungen, ebenso die Gefahr des Kaufgegenstandes gehen für die Zeit vom 1. April 1912 auf den Käufer über. Insbesondere gilt dieses von dem an die Gemeinde Falkenburg zu zahlenden Ratsschuß von 9,34 Mark und der an die Kirche von Falkenburg zu zahlenden Abgabe von 20,50 Mark.

$\S 10$. Der Käufer übernimmt das Kaufobjekt in dem $\mathrm{Zu}$ stande, in dem es sich befindet. Die Haftung für Mängel des Kaufgegenstandes wird ausgeschlossen, irgendwelche besondere Eigenschaften und Vorzüge des Kaufgegenstandes sind nicht zugesichert.

$\S 11$. Ueber das Verhältnis des Umsatzes in der Rezeptur zu dem Umsatze im Handverkauf herrscht Einverständnis; dieserhalb ist keine Garantie übernommen, ebenso nicht für einen bestimmten Umsatz oder Ertrag des Geschäftes für die Zukunft. Verkäufer garantiert aber, daß die von ihm aus dem Umsatzbuch und Warenbezugsbuch angegebenen Zahlen nach bestem Wissen richtig sind.

Darüber, welcher Art Waren in der Apotheke verkauft sind, hat Käufer sich vergewissert. Die Rezepte sind nach bestem Wissen taxiert; sind in der Taxe Fehler vorgekommen, so verzichtet Käufer, dieserhalb Ansprüche betr. des Preises des Kaufgegenstandes geltend zu machen.

$\S$ 12. Das Umsatzbuch und Warenbezugsbuch überläßt Verkäufer dem Käufer drei Wochen zur Einsicht. Nach dieser Zeit hat Käufer die Bücher dem Verkäufer franko zu übersenden.

$\S 13$. Verkäufer versichert, daß ihm über eine Neukonzession, die als Konkurrenz-Apotheke des Kaufgegenstandes in Frage kommen könnte, bis heute nichts zu Ohren gekommen ist.

$\S 14$. Der Warenbezug in den letzten drei Monaten vor Uebergabe des Geschäfts hat vom Verkäufer derart zu geschehen, daß ein Einkauf von Waren in Höhe von 2000 Mark durch Rechnungen vom Verkäufer für diese Zeit nachzuweisen ist.

$\S 15$. Der Verkäufer hat die Kontrollkasse, die Vorschriften für eingeführte eigene Spezialitäten und die Hilfsbücher für die Apotheke dem Käufer auszuhändigen.

$\S 16$. Die ausstehenden Forderungen des Verkäufers in Höhe von 1800 bis 2200 Mark übernimmt Käufer mit $8 \%$ Abschreibung; Käufer zahit die Summe dem Verkäufer dafür am Tage der Uebergabe des Geschäfts in bar aus. 


\section{$-24-$}

§17. Das etwas schadhafte Dach des erkauften Grundstückes verpflichtet sich Verkäufer bis zum 1. April 1912 ausbessern und dichten zu lassen.

Die elektrischen Lichtkörper bleiben im Hausflur, in der Apotheke, im Nebenraum, in den Materialkammern, im Laboratorium und Keller.

Wirtschaftsregale werden nur insoweit vom Käufer übernommen, als Verkäufer es wünscht. Kochherd und Oefen bleiben im Hause. Gartenmöbel, Gartengeräte und -erzeugnisse werden vom Käufer ebenfalls gratis übernommen, wie sie sich am Tage der Uebergabe des Geschäfts vorfinden. Die Einrichtung des Kontors einschließlich der Schreibmaschine verbleiben im Besitze des Verkäufers. Vom Elevenzimmer erhält Käufer die Einrichtung, ausschließlich Kommode und Bettbezüge.

$\S 18$. Verkäufer garantiert, daß die von ihm den Käufer gemachten Angaben betr. Zinsfuß und Zeitdauer 'der Hypotheken richtige sind.

$\S$ 19. Alle durch die Beurkundung des Kaufes, die Auflassung sowie die Eintragung der Eigentumsveränderung und der Hypotheken entstandenen Kosten einschließlich der Stempelkosten trägt Käufer.

§20. Käufer verpflichtet sich, zwecks Erlangung der Konzession die nötigen Schritte nach erfolgter Anzahlung alsbald zu tun.

$\S 21$. Die Uebergabe und Auflassung soll am 1. April 1912 stattfinden. Zur Auflassung bevollmächtigt Käufer den Bürovorsteher L. in Stettin, Verkäufer den Kaufmann M. in Falkenburg mit der Befugnis, Untervollmacht zu erteilen.

$\S 22$. Zur Sicherung für die Erfüllung dieses Kaufvertrages hinterlegt Herr K. am heutigen Tage bei der Pommerschen Bank in Stettin 10000 Mark Ostpreußische Bodenkredit-Aktien mit Zinsscheinen und Kupons, welche zurückzuzahlen sind, nachdem die vereinbarte Anzahlung geleistet und die Auflassung erfolgt ist.

$\S 23$. Käufer ist berechtigt, von diesem Kaufvertrage zurückzutreten, falls ihm wider Erwarten die Konzession zum Betriebe der Apotheke nicht erteilt werden sollte.

Vorstehendes Protokoll ist von mir den Erschienenen vorgelesen, von ihnen genehmigt und eigenhändig unterschrieben wie folgt:

E.

\section{Zur Beglaubigung:}

K.

Victor Schneider

Justizrat, Notar im Bezirke des Preuß. Oberlandesgerichts Stettin. 


\section{IV.Schreiben des Verkäufers an die Regierung zwecks Uebertragung der Konzession.}

Falkenburg, den 1. Februar 1912.

Einer hohen Regierung zu Stettin teile ich hierdurch ganz ergebenst mit, daß mich familiäre Gründe veranlaßt haben, meine Apotheke an Herrn Apotheker K. aus Neustadt, Oberapotheker d. R., zu verkaufen.

Ich bitte höflichst, die mir am 10. März 1904 verliehene Konzession zum Betriebe der hiesigen Adlerapotheke auf meinen Nachfolger übertragen zu wollen.

\section{Hochachtungsvoll}

An die Regierung zu Stettin

Ernst, Apotheker. dizinalrat Dr. Böttinger in Stettin.

\section{Gesuch eines Käufers um Erteilung der Konzession zur Fortführung der gekauften Apotheke.}

Neustadt, den 10. Februar 1912.

Einer hohen Regierung zu Stettin unterbreite ich hiermit das ergebene Gesuch, mir die Konzession zum Betriebe der Adlerapotheke in Falkenburg erteilen zu wollen, nachdem ich das Grundstück von dem bisherigen Besitzer Herrn Apotheker E. gekauft habe.

Ich füge meinem Gesuche bei:

1. Einen kurzen Lebenslauf.

2. Die Approbation als Apotheker.

3. Die Promotions-Urkunde der Universität Greifswald.

4. Die Abschrift einiger Servierzeugnisse.

5. Die Beförderung zum Oberapotheker d. R.

6. Den Kaufvertrag mit Herrn E.

\section{Hochachtungsvoll}

An eine Regierung zu Stettin

K.

z. H. des Herrn Kreisarztes Me-

dizinalrat Dr. Böttinger in Stettin.

Bei Privilegien genügt die einfache Mitteilung an die Regierung, daß man die Apotheke verkauft, resp. gekauft habe. Der Käufer muß jedoch seine Papiere der Regierung mit einsenden. 


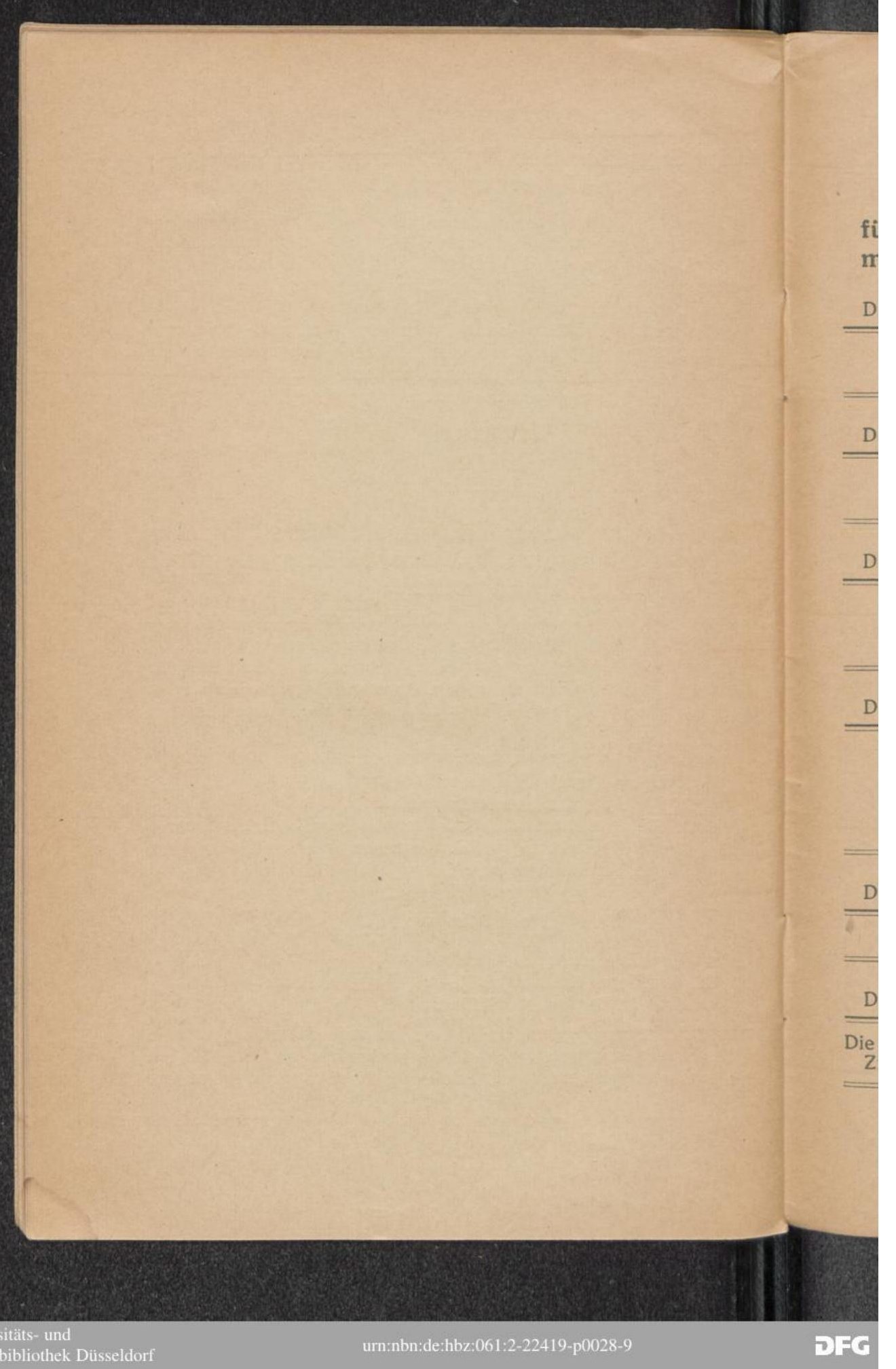




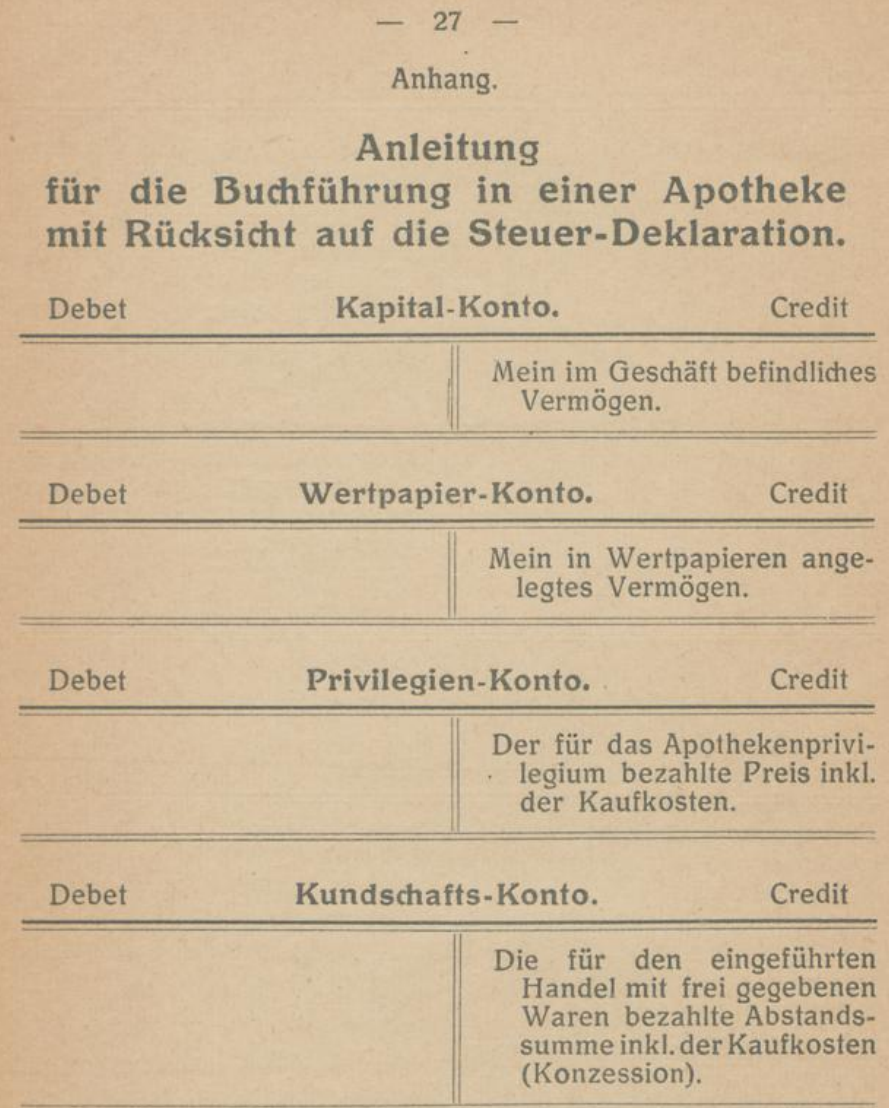

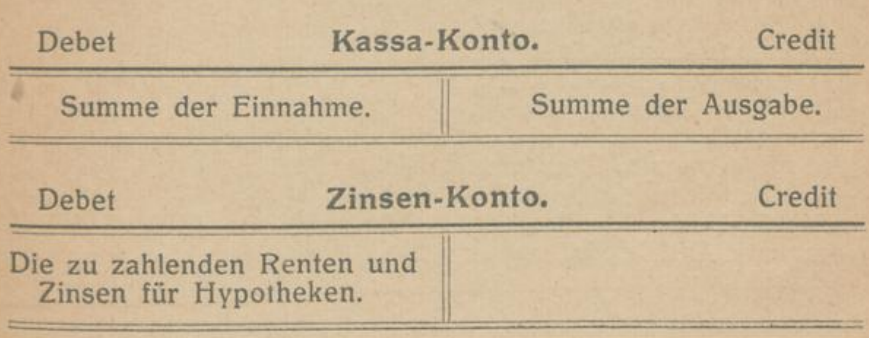


Die Ausgaben für die Verwaltung, Instandhaltung und Reparaturen der Gebäude und sonstige technische Anlagen.
Der von den verpachteten Liegenschaften einkommende Pachtzins.

Der von den vermieteten Räumen einkommende Mietszins.

Der für die selbst bewohnten Räume gültige Mietswert.

Davon sind in Abzug zu bringen die regelmäßigen jährlichen Absetzungen für Abnutzung der Gebäude und zwar ein angemessener Prozentsatz des Wertes.

Feuerversicherung der Gebäude, des Inventars der Warenvorräte

Pacht- und Mietszins.

Heizung u. Beleudtungs kosten.

Löhne inkl. Beköstigung. Kranken- usw. Beiträge. Div. Betriebs - Unkosten: Reklame, Fernsprecher, Eichungskosten, Kassenrabatt, Apoth.-Ztg., Ph.-Ztg., Drogisten-Zeitung, Mineralwasser-Ztg., Vierteliahrsschrift der prakt. Pharmacie, Kaufm. Verein, Mineralw.Fabrik.-Verband, Handelskammer, Apothekenkammer, Haftpflichtversicherung. 
Debet

Waren-Konto.

Credit

Die Anschaffungskosten für die eingekauften Roh- und Hilfsstoffe und Waren, sowie für die sonst im Betriebe erforderlichen Materialien inkl. Portokosten, Frachtgebühr., indirekte Steuern und Zölle, Schreibwaren.
Debet

Privat-Konto.

Credit
Die zur Bestreitung des Haushaltes und zum Unterhalte der Angehörigen gemachten Ausgaben, einschl. des Geldwertes der zu diesem Zweck verbr. Erzeugnisse und Waren des eigenen gewerbl. Betriebes,

d. Staatseinkommensteuern, d. Staatsergänzungssteuern, die Grund- und GebäudeSteuern, sowie Abgaben an Kommunen und andere öffentliche Verbände (Kreis, Provinz), Mietswert der eigenen Wohnung, Apothek.Verein u. Apothek-Kammer, Tageszeitung, Pharmaceut. Wochenschrift usw.
Die für geschäftliche Leistungen jeder Art empfangene Gegenleistungen (Untersuchungsund Revisionsgebühren). Der erzielte Preis für alle gegen bar oder auf Kredit verkaufte Waren und Erzeugnisse. Der Geldwert der zum Gebrauch des Steuerpflichtigen und seiner Angehörigen und der nicht zum Gewerbebetrieb gehaltenen Dienstboten und sonstiger Hausgenossen aus dem Betriebe entnommenen Erzeugnisse und Waren.
Außerordentliche Schenkungen. 
Die Ausgaben für die Instandhaltung und Ergänzung des vorhandenen lebenden und toten Betriebsinventars.
In Abzug zu bringen sind die regelmäßigen jährlichen $\mathrm{Ab}$ setzungen für Abnutzung der Maschinen, Betriebsgerätschaften, und zwar ein angemessener Prozentsatz.

Abzugsfähig, resp. nicht abzugsfähig sind:

\section{Per Grundstücks-Konto.}

Abzugsfähig: Die Ausgaben für Verwaltung, Instandhaltung und Reparatur der Gebäude und sonstigen baulichen Anlagen.

Nicht abzugsfähig sind die für Umbau, Ausbau, bessere Ausstattung oder für die Anlage und Pflege des zur Annehmlichkeit des Besitzers dienenden Hausgartens.

\section{Per Einrichtungs-Konto.}

Abzugsfähig: Die Ausgaben für die Erhaltung und $\mathrm{Er}$ gänzung des vorhandenen lebenden und toten Betriebsinventars.

Nicht abzugsfähig sind die für Geschäftserweiterungen verwendeten Gelder.

\section{Per Waren-Konto.}

$A b z u g s f a ̈ h i g:$ Die Anschaffungskosten für die eingekauften Roh- und Hilfsstoffe und Waren, sowie für die sonst im $\mathrm{Be}$ triebe erforderlichen Materialien einschl.: indirekte Abgaben (Steuern, indirekte, und Zölle), Porto- und Frachtgebühren usw., Schreibwaren usw.

\section{Per Unkosten-Konto.}

Abzugsfähig: 1. Die Kosten für Versicherung der dem Betriebe dienenden Gebäude sowie des lebenden und toten Betriebsinventars und der Warenvorräte gegen Brand und sonstigen Schaden.

2. Der Pacht- oder Mietzins für die zum Geschäftsbetriebe gepachteten oder gemieteten Grundstüdke, Gebäude u. Utensilien.

3. Die Kosten für die im Betrieb erforderliche Heizung und Beleuchtung.

4. Die:Löhnung der für den Gewerbebetrieb angenommenen Angestellten, Gehilfen, Lehrlinge, Arbeiter, einschl. der etwaigen Gratifikationen usw. und des Geldwertes der etwa zu ge- 
währenden Beköstigung und sonstigen Naturalleistungen, soweit diese nicht aus den Betriebsbeständen entnommen werden, sowie die für diese Personen zu entrichtenden Beiträge zu Kranken- und ähnlichen Kassen (Alters- und Berufsgenossenschaft).

5. Die zur Erwerbung, Sicherung und Erhaltung des Einkommens sonst noch verwendeten Ausgaben, soweit solche als Betriebsunkosten anzusehen und nicht bereits an anderer Stelle verrechnet sind.

Es gehören hierzu:

a) Kosten für die Reklame (Stadt- oder Kreisblatt),

b) die durch den Betrieb erforderlich gewordenen Gebühren für Fernsprecher, Depeschen, Eichungs-, Druckproberevision,

and-

ichen

c) der den Krankenkassen eingeräumte Rechnungsrabatt,

d) die Kosten der für den Betrieb erforderlichen Zeitungen: Pharm. Ztg., Apoth.-Ztg., Drogisten-Ztg., MineralwasserZtg., Vierteljahresschrift für prakt. Pharmacie, Centralblatt für Chemie und Pharmacie usw.,

e) Beiträge zum Kaufm. Verein, Verband der Mineralwasser-Fabrik, Handels- und Apotheken-Kammer,

f) Haftp flichtversicherung.

itars.

ngen

uften

Be-

aben

hren

\section{Per Zinsen-Konto.} Renten.

Abzugsfähig: Die zu zahlenden Schuldenzinsen und

Nicht abzugsfähig sind:

1. die zur Bestreitung des Haushaltes und zum Unterhalte der Angehörigen gemachten Ausgaben, einschließlich des Geldwertes der zu diesem Zweck verbrauchten Erzeugnisse und Waren des eigenen gewerbl. Betriebes. Ferner

dem toten und

riebe ilien. zung

2. die Staats-Einkommen-Steuer,

3. die Grund- und Gebäude-Steuer,

4. Sowie andere Abgaben an kommunale oder andere öffentliche Verbände (Kreis, Provinz) usw.,

5. der Mietswert der eigenen Wohnung,

6. Beitrag zum Apotheker-Verein und anderen Vereinen,

7. die Kosten der $z$ ur Unterhaltung und eigenen Belehrung gehaltenen Zeitschriften und Bücher. 


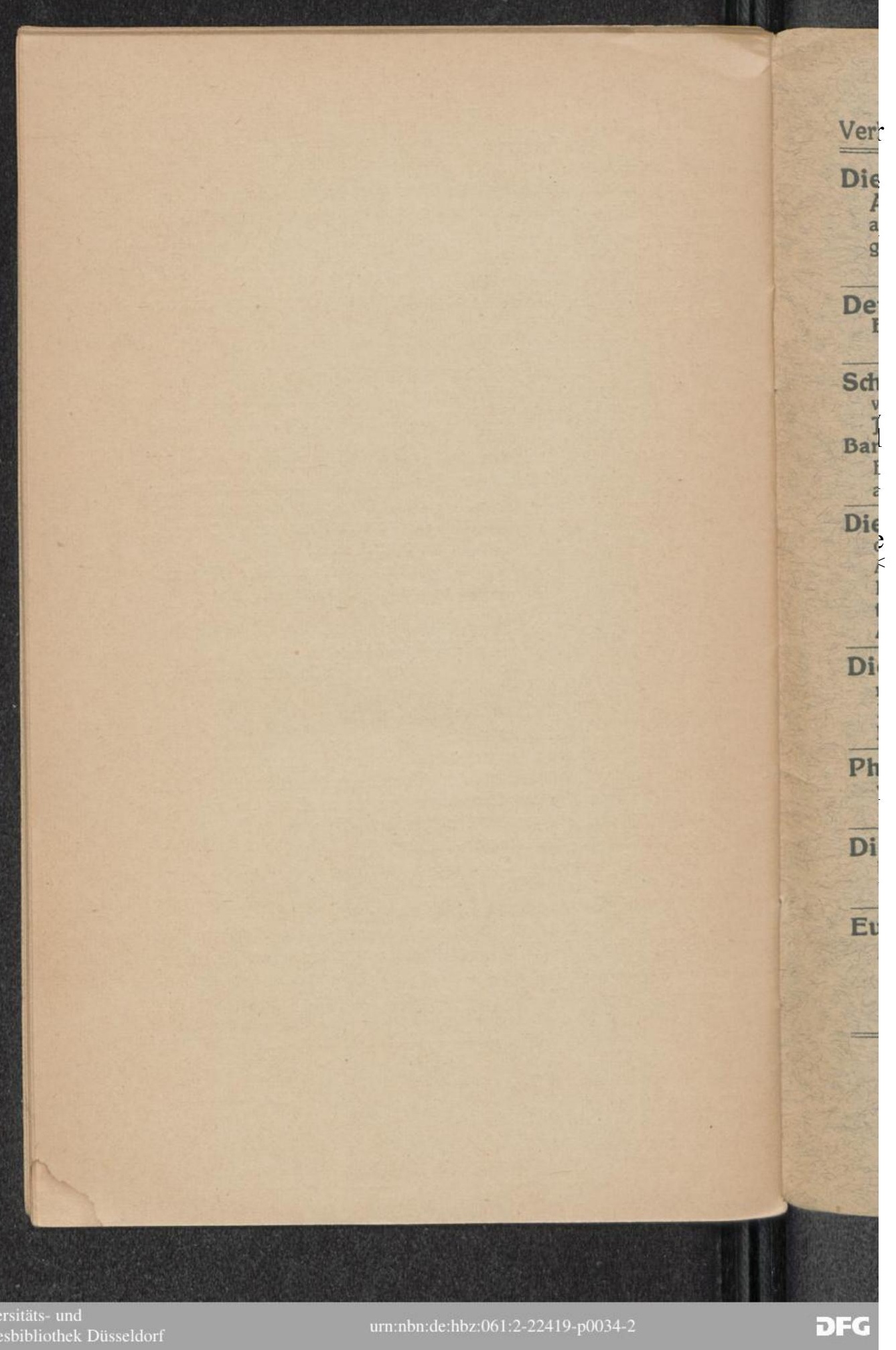


Verlag von Julius Springer in Berlin W. 9

Die kaufmännische Buchführung in der Apotheke. Nach bequemem und brauchbarem Verfahren an der Hand eines Beispiels in leicht faßlicher Weise dargestellt von Dr. W. Mayer, Apotheker.

Kartoniert Preis M. 1.60

Der Apotheker als Geschäftsmann. Von Dr. E. Mylius, Besitzer der Engelapotheke in Leipzig.

Preis M. 2.40

Schule der Pharmazie in fünf Bänden, herausgegeben von Prof. Dr. H. Thoms, Dr. E. Mylius, Prof. Dr. K. F. Jordan, Prof. Dr. E. Gilg.

Band I: Praktischer Teil. Bearbeitet von Dr. E. Mylius. Fünfte, vermehrte und verbesserte Auflage. Mit 143 Textabbildungen.

Preis gebunden M. 16.-

Die preußischen Apothekengesetze mit Einschluß der reichsgesetzlichen Bestimmungen über den Betrieb des Apothekergewerbes. Herausgegeben und erläutert von Dr. H. Böttger und E. Urban, Redakteure der Pharmazeutischen Zeitung. Fünfte, neubearbeitefe und vervollständigte Auflage.

Preis gebunden M. 7.-

Die preußische Apothekenbetriebsordnung mit den ergänzenden Verordnungen und Erlassen. Von Ernst Urban, Redakteur der Pharmazeutischen Zeitung. Dritte, neubearbeitete Auflage.

Preis M. 2.-

Pharmazeutischer Kalender 1920. Herausgegeben von Ernst Urban. 49. Jahrgang, 2 Teile. I. Teil gebunden, II. Teil geheftet.

zusammen Preis M. 9.-

Die Apothekenhelferin. Ein Lern-und Nachschlagebuch von Dr. Otto Gerke, Apotheker. Mit 25 Textab. bildungen.

Preis M. 4.80

Eugen Dieterich, Neues pharmazeutisches Manual. Dreizehnte, wenig veränderte Auflage. Von Prof. Dr. Karl Dieterich, Direktor der Chemischen Fabrik Helfenberg, A.-G., vorm. Eugen Dieterich. Mit 148 Textfiguren.

Unter der Presse

Hierzu Teuerungszuschläge. 
Drudk von C. Brendel, Zeitz 